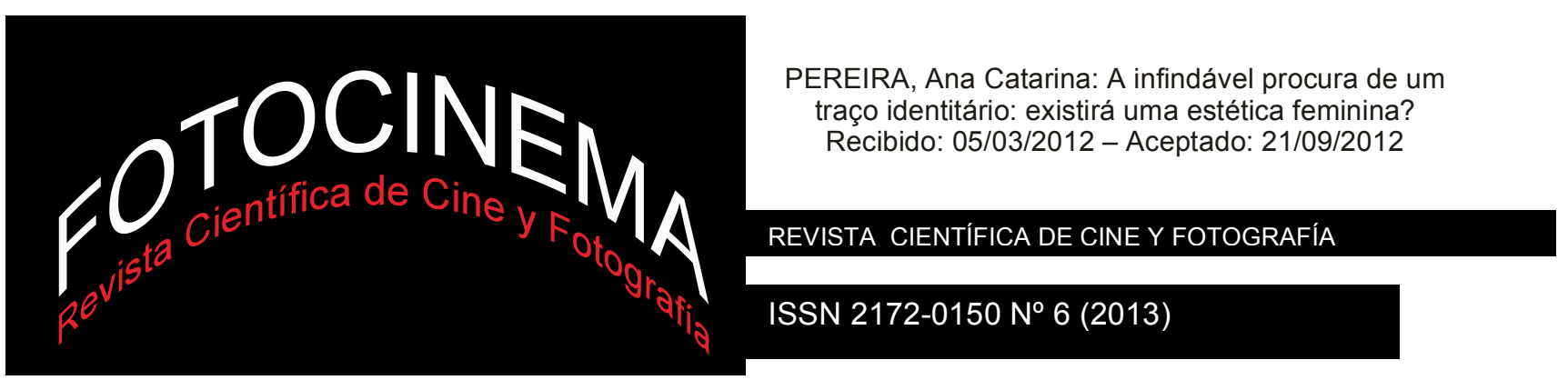

\title{
A INFINDÁVEL PROCURA DE UM TRAÇO IDENTITÁRIO: EXISTIRÁ UMA ESTÉTICA FEMININA?
}

\section{THE NEVER-ENDING SEARCH FOR AN IDENTITY MARK: IS THERE A FEMININE AESTHETIC?}

\author{
Ana Catarina Pereira \\ Universidade da Beira Interior
}

\section{Resumo:}

No âmbito das teorias feministas do cinema, e dos estudos fílmicos em geral, algumas questões têm sido levantadas ao longo das últimas décadas, nomeadamente no que diz respeito à exigência de uma maior representatividade feminina no mundo da realização e produção cinematográficas. Sendo o olhar do espectador, como Laura Mulvey sugeriu, pressupostamente masculino, treinado por realizadores com fantasias e tendências voyeuristas homogéneas, a questão seguinte seria inevitável: poderá este mesmo olhar assumir características distintas, quando mediado por uma mulher? Poderá a arte, ao contrário dos anjos, ter sexo? Existirá, neste sentido, uma "estética feminina", como Silvia Bovenschen, em artigo homónimo, publicado em Setembro de 1976, procura antecipar? Procurá-la não implicará um aprofundar de estereótipos associados à feminilidade e à masculinidade, todos eles redutores, segundo o ponto de vista de Michel Foucault e Judith Butler, bem como a atribuição de um certo carácter de exotismo, pela falta de representatividade nos circuitos artísticos? Enunciando e debatendo os principais argumentos dos autores mencionados, propomo-nos, no presente artigo, responder às questões colocadas.

\section{Palavras-chave:}

voyeurismo; espectadora; ausência; receptividade; identificação.

\section{Key words:}

voyeurism; female spectator; absence; receptivity; identification.

\begin{abstract}
:
In the context of feminist theories of cinema, and film studies in general, some questions have been raised in the past few decades, concerning the need for a greater representation of women in the world of film making and production. Accepting the idea of a viewer gaze, as Laura Mulvey suggested, supposedly male, trained by directors with fantasies and uniformed voyeuristic tendencies, the next question is inevitable: might this gaze have different characteristics when mediated by a woman? Can the art, unlike the angels, have sex? Is there, in this sense, a "feminine aesthetic", as Silvia Bovenschen, on an article with the same name, published in September 1976, looks forward to anticipate? To look for it does not imply a deepening of stereotypes associated with femininity and masculinity, all reducers, according to the point of view of Michel Foucault and Judith Butler, as well as the assignment of a certain exoticism' character, motivated by the lack of representation in the art circuit? Outlining and discussing the main arguments of the authors above mentioned, we propose, in this paper, to answer these questions.
\end{abstract}




\section{Resumen}

"Las mujeres son diferentes, y una manifestación natural de esta diferencia (nota bene!) es precisamente el hecho de que son incapaces de producir arte" (Bovenschen, 1976: 115).

Haciéndose eco del paralelismo ya realizado por Simone de Beauvoir en el ensayo El segundo sexo, Silvia Bovenschen vuelve, en un artículo publicado en 1976 que nos proponemos discutir aquí, a la asociación asumida entre una perspectiva descriptiva masculina y la verdad absoluta. En su opinión, el dominio de la producción artística por el género masculino habrá originado una inaccesibilidad y una extrañeza relativas a la otra mitad de la población, que se denuncia por el carácter de exotismo que muchos críticos votaron a los pocos, y de cierta forma lejos entre si mismos, objetos culturales producidos por las mujeres, a lo largo de la historia. Otra consecuencia natural de este fracaso, descrito por el uso del término déficit, importado del lenguaje economicista, todavía sería, a nuestro juicio, una segregación de la dicha producción en una sola clase: una escritura femenina, una mirada femenina, un rasgo femenino. Con la restricción, la incertidumbre se multiplica: la escritura femenina es la que centra su atención en mujeres fuertes y decididas, la que demuestra una sensibilidad $y$ capacidad de observación característica de un género, o la que construye una narrativa entrecruzada, por la sociológicamente establecida capacidad de realizar múltiples tareas asociadas al mismo sexo?

En este sentido, hay que recordar que las propias teorías feministas han enfrentado críticas con relación a un intento forzado de universalización de lo que constituye "ser mujer", fuertemente cuestionada por autores como bell hooks (1999), para quien la experiencia se traducía en una visión reductiva: ser blanca, heterosexual y de clase media. Junto con este concepto, Judith Butler argumenta aún en contra de la categoría "género" (aunque promovida por el feminismo como una forma de desafiar y rechazar la definición de la naturaleza de la mujer por su biología), por la considerar igualmente normalizadora, restringida a una oposición binaria entre femenino $y$ masculino $y$ complementada con un supuesto heterosexual: "La idea de que podría haber una 'verdad' del sexo, como Foucault irónicamente la determina, se crea precisamente por prácticas normativas que generan identidades coherentes a través de una matriz de reglas de género igualmente coherentes. La heterosexualización del deseo exige y establece la producción de oposiciones discretas y asimétricas entre 'femenino' y 'masculino', entendidos estos conceptos como atributos que describen 'hombre' y "mujer"' (Butler, 1999: 23).

Evidenciando una fuerte influencia de Foucault, Butler sostiene que el acto mismo de la definición de una identidad de género excluye o devalúa ciertos cuerpos, prácticas y 
discursos, ocultando al mismo tiempo el carácter construido (y discutible) de la misma identidad. Aplicando las conceptualizaciones formuladas, buscaremos, en este artículo, contestar a la pregunta: ¿tiene sentido buscar una estética femenina?

Palabras clave: vouyerismo; espectadora; ausencia; receptividad; identificación

\section{Introdução}

Para Silvia Bovenschen, a ausência de mulheres nos diversos circuitos artísticos é evidenciada por um pragmatismo matemático dificilmente contornável. Nesse sentido, relembra o escasso número de mulheres que, no século XX, fazem parte da história da literatura, do cinema, da dramaturgia, da pintura ou da composição musical, por comparação com os seus colegas do sexo masculino. A título de exemplo, recorde-se ainda a lista recentemente divulgada pela revista Sight and Sound, dos 250 filmes mais importantes da História do Cinema, da qual apenas fazem parte sete filmes de mulheres cineastas ${ }^{1}$. No entanto, para além desta falta de representatividade, a autora considera que outro tipo de consequências advém desta invisibilidade. Nesse sentido, afirma: "A ausência de mulheres dos aposentos santificados nos quais lhes foi proibida a entrada é agora apresentada como uma prova da sua extraordinária falta de capacidade." (Bovenschen, 1976: 116)².

A uma primeira fase de luta contra o surgimento de uma produção artística feminina, a sociologia encarregar-se-ia, no entender de Bovenschen, de suceder uma fase de explanação das dificuldades e obstáculos que as mulheres necessitam transpor para atingir um escasso número de

\footnotetext{
1 Da lista mencionada fazem parte os seguintes filmes, realizados por mulheres: Jeanne Dielman, 23 quai du Commerce, 1080 Bruxelles (Chantal Akerman: 1975), Beau Travail (Claire Denis: 1999), Meshes of the Afternoon (Maya Deren/Alexander Hammid: 1943), Daisies (Vera Chytilova: 1966), Cleo from 5 to 7 (Agnès Varda: 1962), Wanda (Barbara Loden: 1970), The Piano (Jane Campion: 1993). A lista pode ser consultada, na íntegra, em: http://explore.bfi.org.uk/sightandsoundpolls/2012

2 Tradução da autora. Versão original: "Women's absence from the hallowed chambers to which they were denied entry is now presented as evidence of their extraordinary lack of ability.”
} 
representantes em termos de produção artística. Suspeitando fortemente da mudança operada, que considera perigosa e de retorno ao obscurecimento das diferenças entre ambos os sexos (como se não existissem mulheres e homens mas antes uma sociedade composta única e exclusivamente por seres humanos), Bovenschen qualifica esta assimilação como absurda. Ignorar as diferenças de experiências realizadas pelos dois sexos implica, na opinião da autora, o prosseguimento da estratégia daqueles que criaram e mantiveram a sociedade patriarcal e que, em simultâneo, procuraram abortar os esforços da descoberta feminina de capacidades e necessidades próprias. Ao pensamento pós-moderno que se tenta incutir desde meados do século passado até à contemporaneidade, segundo o qual "As mulheres podem fazer exactamente o mesmo que os homens", a autora contrapõe a questão: "Nós quereremos realmente fazer as mesmas coisas que os homens?"3 (Bovenschen, 1976: 117).

Tentando contrariar estereótipos e imagens pré-concebidas, Silvia Bovenschen considera que as eternas dualidades "receptividade versus produtividade" e "sensibilidade versus racionalidade", associadas às diferenciações entre os sexos, não podem ser destruídas por mera justaposição. Para a autora, a imagem da mulher ligada à receptividade e à sensibilidade é tão utópica quanto a sua distanciação de comportamentos agressivos ou competitivos. Numa sociedade patriarcal, e compelidas pela necessidade de sobrevivência na mesma, Bovenschen defende que as mulheres terão que continuar a fazer uso deste último tipo de comportamento, resultando a obra produzida do vasto conjunto de vivências experienciadas: "A produção artística feminina ocorre através de um processo complicado que envolve conquista e reclamação, apropriação e formulação, bem como esquecimento e subversão.” (Bovenschen, 1976: $134)^{4}$.

\footnotetext{
3 Tradução da autora. Versão original: “'We women can do just as much as men' (...). The question is, do we want to do just as much as men, or the same thing as men?"

4 Tradução da autora. Versão original: "Feminine artistic production takes place by means of a complicated process involving conquering and reclaiming, appropriating and formulating, as well as forgetting and subverting".
} 
Por último, e tentando responder à questão com que intitula o seu artigo, a autora relembra que, se por um lado a arte tem sido sobretudo produzida por homens, também foram estes que estabeleceram os padrões de avaliação da mesma. No caso específico do cinema, o exercício de contabilização de mulheres críticas seria ingrato e infrutífero. Na sua opinião, é importante reconhecer o terrível efeito causado pela deformação cultural e histórica na supramencionada subjectividade feminina, pelo que se questiona: "Poderão as mulheres 'ser apenas mulheres', reduzidas ao elemento Ser?” (Bovenschen, 1976: 119)5 A sua resposta é tendencialmente negativa, tendo em conta que os meios de expressão artística não foram originalmente criados por mulheres, nem sequer escolhidos por estas, o que dificulta a elaboração e desenvolvimento de uma estética feminina.

\section{Cinema feminino versus cinema masculino}

Na sequência da publicação destes primeiros artigos/manifestos pela defesa de uma maior produção artística feminina, Teresa de Lauretis viria afirmar, em Aesthetic and feminist theory: rethinking women's cinema (1985), que os anos 70 corresponderam à enfatização de uma dicotomia entre as preocupações do movimento feminista e a descodificação dos dispositivos cinematográficos utilizados: por um lado, foi lançado um apelo à imediata realização de propostas de activismo político, consciencialização, autoexpressão e transmissão de "imagens positivas" de mulheres; por outro, considera Lauretis, insistiu-se num trabalho rigoroso e formal no universo cinemático, tendo em vista a desconstrução e análise dos códigos ideológicos embebidos na representação.

A este respeito, também Silvia Bovenschen sustenta, no artigo citado, que a verdadeira luta na qual as mulheres artistas foram capturadas foi a da oposição entre as exigências feministas de uma produção temática e as exigências formais de um objecto cultural e/ou mediático. No caso específico da sétima arte, Laura Mulvey declara ter havido um período marcado pelo

5 Tradução da autora. Versão original: "Can women just 'be women', reduced to some elemental Being?”.

80 
esforço de alterar o conteúdo da representação - “mistura de consciencialização e propaganda" (Mulvey, 1989: 121) ${ }^{6}$ no qual se incentiva a captação de imagens de mulheres reais, que descrevam as suas experiências de vida. Gillian Armstrong, Elaine May e Chantal Akerman serão algumas das realizadoras mais associadas a esta militância, compreendendo as necessidades de realismo e denúncia de uma desigualdade de direitos e oportunidades.

A esta fase inicial ter-se-á seguido um momento no qual a preocupação com a linguagem da representação se tornou predominante. A fascinação com o processo cinemático terá então levado realizadores e críticos "a utilizarem e a interessarem-se pelos princípios estéticos e pelos termos referenciais fornecidos pela tradição vanguardista” (Mulvey, 1989: 122)7. Neste último período, atenta Mulvey, o interesse comum do cinema vanguardista e do feminismo pela política da imagem (ou pela dimensão política da expressão estética) conduziu a uma proliferação de debates teóricos sobre a linguagem e a criação de imagens que extravasaram o cinema e que se alargaram ao âmbito de disciplinas como a semiótica, a psicanálise e a teoria crítica. Argumentou-se então que, para contrariar a estética do realismo (irremediavelmente comprometida com a ideologia burguesa e com o cinema de Hollywood), os realizadores vanguardistas e feministas deveriam assumir uma posição contrária à do "ilusionismo" narrativo e a favor do formalismo. O pressuposto era o de que "colocando em primeiro plano o próprio processo, privilegiando o significante, iria necessariamente romper-se a união estética e forçar a atenção do espectador a centrar-se nos meios de produção de significado" (Mulvey, 1989: 122) .

Analisando as considerações de Bovenschen e Mulvey, Teresa de Lauretis, no artigo acima citado, considera que ambas as autoras se prenderam ao

\footnotetext{
6 Tradução da autora. Versão original: "a period characterized by a mixture of consciousnessraising and propaganda."

7 Tradução da autora. Versão original: "the use of and interest in the aesthetic principles and terms of reference provided by the avant-garde tradition."

8 Tradução da autora. Versão original: "foregrounding the process itself, privileging the signifier, necessarily disrupts aesthetic unity and forces the spectator's attention on the means of production of meaning."
} 
compromisso político do movimento e à necessidade de construção de outras representações da mulher. $\mathrm{Na}$ sua opinião, a forma como colocaram a questão da expressão (uma "estética feminina" e uma "nova linguagem do desejo”) foi de encontro a uma noção de arte tradicional, já proposta pela estética modernista. Bovenschen, por um lado, apenas terá exigido uma saída da produção artística feminina da esfera do lar e a consequente entrada em museus e galerias (a arte com um valor de troca, só existindo de acordo com padrões estéticos socialmente estabelecidos); enquanto Mulvey, por outro, ao apresentar a destruição da narrativa e do prazer visual como principal objectivo de um cinema de mulheres, elogia uma tradição, ainda que radical, já previamente estabelecida: a histórica visão esquerdista e vanguardista de Eisenstein, Vertov e Godard.

Discordando com ambas as perspectivas (de Bovenschen e Mulvey), Teresa de Lauretis afirma que tentar distinguir as marcas de um cinema feminino (realizado por mulheres) e de um cinema masculino (realizado por homens) é uma questão essencialmente retórica: "Está realmente lá, no ecrã, no filme, inscrito na sua montagem lenta de longos planos, e na continuidade das imagens nos seus enquadramentos silenciosos; ou estará antes na nossa percepção, no nosso ponto de vista, como -precisamente- um limite subjectivo e uma fronteira discursiva (género), um horizonte de significado (feminismo), que é projectado nas imagens, no ecrã, à volta do texto?” (Lauretis, 1985: 162)9.

Na opinião de Lauretis, a questão deverá, de facto, iniciar-se no artista atrás da câmara -o olhar ou o texto como origem e determinante de significadopartindo, posterior e necessariamente, em direcção à esfera pública do cinema enquanto tecnologia social. Para a autora, o entendimento das implicações do cinema deverá ser potenciado em convergência com outros modos de representação cultural e nas suas possibilidades de produção e contra produção de visões sociais. Tal projecto implica, considera a própria,

9 Tradução da autora. Versão original: "Is it actually on screen, in the film, inscribed in its slow montage of long takes and in the stillness of the images in their silent frames; or its rather in our perception, our insight, as - precisely- a subjective limit and discursive boundary (gender), an horizon of meaning (feminism) which is projected into the images, onto the screen, around the text?". 
repensar o cinema de mulheres como gerador de uma crítica política e de uma visão social feminista. Segundo afirma, "o feminismo não inventou apenas novas estratégias ou criou novos textos, mas, mais importante, concebeu um novo sujeito social, as mulheres: como oradoras, escritoras, leitoras, espectadoras, consumidoras e produtoras de modelos culturais" (Lauretis, 1985: 163)10. É por esta razão que, para Teresa de Lauretis, o projecto de um cinema de mulheres deixa de ser o de destruir ou perturbar a visão centrada do homem, representando os seus "lugares cegos", as suas lacunas ou as suas repressões. O esforço e o desafio contemporâneos traduzem-se, no seu entender, na efectivação de um olhar distinto: "construir outros objectos e sujeitos de visão e formular as condições de representação de outro objecto social" (Lauretis, 1985: 163) ${ }^{11}$.

Para concretizar a sua formulação teórica, cita como exemplo o filme Jeanne Dielman, 23 Quai du Commerce, 1080 Bruxelles, de Chantal Akerman (1975), que considera dirigir-se ao espectador como feminino, não pela "beleza das imagens", nem pela composição equilibrada dos enquadramentos, ausência de ângulos inversos ou edição perfeitamente calculada da sua câmara fixa, numa narrativa espacial contínua, lógica e obsessiva. Para Lauretis, esta é uma obra que denuncia uma mulher atrás da câmara pela forma como a personagem principal é filmada: “(...) são acções de uma mulher, gestos, o corpo e o olhar que definem o espaço da nossa visão, a temporalidade e os ritmos da percepção, o horizonte de significado disponível para o espectador." (Lauretis, 1985: 159)12. Deste modo, acrescenta a autora, a narrativa suspensa não é construída com base na expectativa de um acontecimento ou acções significativos (que acabam por acontecer, de forma inesperada, no final do filme), mas antes nos deslizes que interrompem a rotina de Jeanne: “os pequenos esquecimentos, as

10 Tradução da autora. Versão original: "Feminism has not only invented new strategies or created new texts, but more importantly it has conceived a new social subject, women: as speakers, writers, readers, spectators, users and makers of cultural forms".

${ }_{11}$ Tradução da autora. Versão original: "The effort and challenge now are how to effect another vision: to construct other objects and subjects of vision, and to formulate the conditions of representability of another social subject".

12 Tradução da autora. Versão original: “(...) it is a woman's actions, gestures, body and look that define the space of our vision, the temporality and rhythms of perception, the horizon of meaning available to the spectator." 
hesitações que ocorrem em tempo real nos gestos mais insignificantes como o de cortar batatas, lavar os pratos ou fazer café - e depois não o beber. $\mathrm{O}$ que o filme constrói -formal e artisticamente- é um retrato de uma experiência feminina, da duração, percepção, acontecimentos, relações e silêncios, que se sentem como imediata e inquestionavelmente verdadeiros." (Lauretis, 1985: 159)13.

A este respeito, a própria realizadora faria uma análise semelhante, ao assumir Jeanne Dielman (...) como um filme feminista. Em 1977, em entrevista à revista Camera Obscura, Chantal Akerman afirmava que a sua originalidade residia no facto de, pela primeira vez, ter mostrado em cinema os gestos diários de uma mulher: "Eles são os mais baixos numa hierarquia de imagens fílmicas... Mas mais do que o conteúdo, é uma questão de estilo. Quando escolhes mostrar os gestos de uma mulher de uma forma tão precisa é porque os amas. De alguma forma, reconheces esses gestos que sempre foram recusados e ignorados" (Akerman, 1977: 118)14. Não poupando críticas às suas colegas de profissão, a cineasta defende ainda que são raros os casos em que uma mulher tem confiança suficiente para avançar através dos seus sentimentos, optando por uma simplicidade óbvia em termos de conteúdo e narrativa: "Elas esquecem-se de procurar maneiras formais de expressar o que são e o que querem, os seus próprios ritmos, as suas próprias formas de olhar para as coisas. Muitas mulheres têm um desprezo inconsciente pelos seus sentimentos. Mas eu acho que não tenho isso. Eu tenho confiança suficiente em mim mesma. Essa é a outra razão pela qual eu o considero um filme feminista - não apenas por aquilo que ele diz, mas por aquilo que ele mostra, e como o mostra." (Akerman, 1977: 119)15.

13 Tradução da autora. Versão original: "the small forgettings, the hesitations between realtime gestures as common and 'insignificant' as peeling potatoes, washing dishes or making coffee - and then not drinking it. What the film constructs - formally and artfully, to be sure - is a picture of female experience, of duration, perception, events, relationships and silences, which feels immediately and unquestionably true."

${ }^{14}$ Tradução da autora. Versão original : "They are the lowest in the hierarchy of film images... But more than the content, it's because of the style. If you choose to show a woman's gestures so precisely, it's because you love them. In some way you recognize those gestures that have always been denied and ignored."

15 Tradução da autora. Versão original: "They forget to look for formal ways to express what they are and what they want, their own rhythms, their own way of looking at things. A lot of 
Outro caso paradigmático, mais recente e múltiplas vezes citado como exemplo de uma realizadora que corresponde ao perfil procurado pelas teóricas feministas do cinema, é o de Jane Campion. Lisa French, investigadora australiana da RMIT University, analisa, na sua tese de doutoramento (French, 2007), a forma como a experiência feminina e o desejo são retratados nos seus filmes. Para introduzir o tema, a especialista lança algumas questões centrais, nomeadamente:

- As personagens, as imagens e a própria câmara revelam uma identificação feminista e/ou feminina da realizadora?

- Jane Campion reflectirá o seu próprio género nas representações que constrói?

- Poderá este género ser observado nos seus filmes através de elementos como a estética, a linguagem, ou uma visão particular do que é ser mulher?

$\mathrm{Na}$ opinião de French, os filmes de Jane Campion expressam uma visão indubitavelmente feminista, por se centrarem em temas como a desigualdade entre homens e mulheres, a dificuldade em crescer como mulher numa sociedade desigual, o desejo e a sexualidade feminina. As protagonistas assumem invariavelmente personalidades fortes, lutando contra uma sociedade que as asfixia. Para além disso, segundo a investigadora, a equipa artística com que Jane Campion habitualmente trabalha é maioritariamente constituída por mulheres o que, dada a reduzida percentagem de profissionais do sexo feminino no sector, é um factor a sublinhar.

Segundo dados estatísticos que Lisa French apresenta, ficou também provado que as espectadoras-mulheres se identificaram com os dois filmes mais conhecidos de Jane Campion: Piano (1993) e Holy Smoke (1999). Para Jane Campion, este reconhecimento está sobretudo relacionado com o facto de ter tentado redefinir o desejo feminino no cinema: "Como mulher, tens uma visão única e diferente. É bom que estas vozes sejam escutadas em todo confidence in myself. So that's the other reason why I think it's a feminist film - not just what is says but what is shown and how it's shown." 
o mundo." (French, 2007: 3) 16 $^{16}$ Apesar de considerar a definição "feminista" como limitada para caracterizar o seu trabalho, a realizadora assume centrarse em personagens fortes que enfurecem o patriarcado e conclui: "Eu penso que sei coisas sobre as mulheres que os homens não conseguem exprimir" (French, 2007: 125) ${ }^{17}$.

\section{A arte (e o cinema) feminista como arma política}

Depois das décadas de 60 e 70 terem marcado a entrada das mulheres no universo artístico, os anos 80 correspondem a um período de teorização e reflexão sobre o mesmo fenómeno. As vozes e expressões destas mulheres, que frequentemente manifestavam um profundo descontentamento pela invisibilidade a que eram votadas, começam então a ser encaradas como instrumento político de consciencialização e transmissão de valores. Neste sentido, a revista Screen publica, em 1980, um artigo no qual é definida uma estratégia política para a realização de mudanças sociais através da arte. A multifacetada artista norte-americana Judith Barry e a investigadora Sandy Flitterman são co-autoras deste manifesto que começa por afirmar categoricamente: "Para que se possa desenvolver uma prática artística feminista que resulte na produção de uma mudança social, é necessário entender a representação como um tema político e proceder a uma análise da subordinação da mulher dentro das formas de representação patriarcais" (Barry et Flitterman, 1980: 35)18. Para as autoras, é portanto fundamental que se volte a discutir, de um ponto de vista feminista, as noções de arte e política, bem como as relações entre ambas, tendo em conta o facto de a própria feminilidade ser socialmente construída.

Como já referimos anteriormente, o início dos movimentos feministas enfatizaram a importância de dar voz às experiências pessoais das mulheres,

${ }^{16}$ Tradução da autora. Versão original: "As a woman you have a unique and different vision. It's good that these voices are heard in the world."

${ }_{17}^{17}$ Tradução da autora. Versão original: "I think I know things about women that men cannot express."

18Tradução da autora. Versão original: "In order to develop a feminist artistic practice that works towards productive social change, it is necessary to understand representation as a political issue and to have an analysis of women's subordination within patriarchal forms of representation."

86 
de forma a documentar a discriminação e a opressão de que estas eram vítimas, transformando-se a arte num veículo de libertação. No entanto, movimentos posteriores com os quais Barry e Flitterman partilham pontos de ligação têm defendido que uma arte feminista deverá ser concretizada para além dos sentimentos, necessidades e desejos femininos, para que possa resultar numa verdadeira transformação das estruturas opressivas. Apesar de reconhecerem que formas de arte mais militantes e politicamente radicais concretizam o seu valor na produção de resultados imediatos (como a expressão de raiva ou dor face a casos de violência doméstica, ou outros, nos quais as mulheres são maioritariamente vítimas), as autoras consideram que estes são temporariamente limitados. No entender de ambas, só uma nova abordagem teórica, radical e feminista sobre a arte, que inclua questões ideológicas, culturais e de produção de significado, poderá expressar as causas (em vez dos efeitos) da opressão que vitimiza inúmeras mulheres. Reiterando que todos os actos (desde comer uma laranja a construir uma mesa, passando por ler um livro) são actos sociais, Barry e Flitterman sublinham que uma relativa selecção ou valorização é permanentemente levada a cabo pela cultura dominante de cada sociedade, dentro da multiplicidade possível de significados de cada acto. Nesta perspectiva, uma abordagem teórica que considere a variedade de fenómenos culturais terá que produzir os meios de verificação da efectividade da arte feminista, o que significa que, para Barry e Flitterman, discutir os efeitos políticos de um trabalho artístico implica a realização de um questionamento específico: “Acção, levada a cabo por quem, e com que propósito?” (Barry et Flitterman, 1980: 36) ${ }^{19}$.

Para melhor definirem o que entendem por arte feminista com efectividade política, as autoras recuperam a divisão anteriormente criada por Laura Mulvey, em entrevista à revista Wedge ( ${ }^{0}$ 2, Primavera 1978). O primeiro tipo de arte que incluem dentro deste género pode ser visto como uma espécie de glorificação de um poder feminino essencial, com base na crença de que existe uma essência feminina a residir algures no corpo da mulher, e

19 Tradução da autora. Versão original: “Action, by whom, and for what purpose?” 
que esta poderá ser encontrada em quadros ou esculturas que o valorizem. Sendo este tipo de arte frequentemente associado a um misticismo e a uma ideia de mitologia feminina - que as autoras consideram elevar a auto-estima da mulher, numa sociedade que produz o efeito contrário - apresenta como principal desvantagem a falta de sustentação teórica de representação, de imagens que não geram questionamento nem constroem qualquer problemática. Na opinião de ambas, as contradições do termo "feminilidade" não são aqui abordadas nem desafiadas, mas antes tidas como socialmente aceites e incontestáveis. Desta forma, em vez de constituírem trabalhos progressistas, como seria desejável, são antes retrógrados, citando como exemplos os trabalhos Gina Pane que, durante a década de 70, se tornou um ícone da body art e da escultora, fotógrafa e video artist Hannah Wilke. ${ }^{20} \mathrm{~A}$ arte é aqui centrada na dor e no prazer erótico, não desafiando, no entender das autoras, a rigidez da categorização "ser mulher". Ainda que a mensagem seja transmitida de um ponto de vista valorizador (a mulher como suporte de uma cultura), que poderia encarar-se como progressista, esta acaba por produzir um retrocesso, perpassando um conceito de feminilidade como a essência imutável da arte.

Um segundo tipo de arte encara a mulher como uma forma de resistência sub-cultural. Destacando o trabalho artesanal, frequentemente ignorado pelos sistemas de representação, Barry e Flitterman propõem uma reconstrução da "história escondida" relacionada com a produção e tradição femininas (Barry et Flitterman, 1980: 40). Abolindo a distinção entre elevadas ou baixas formas de produção cultural, este tipo de arte destaca as mulheres como as criativas que a cultura mainstream teima em não reconhecer, não sendo, no entanto, capaz de transformar as condições estruturais de produção artística, pela idêntica falta de estratégia teórica e de relação dialéctica com a cultura masculina dominante. As autoras consideram assim que este tipo de arte acaba por assimilar, ainda que sem querer, o estatuto de alternativa ou nicho de mercado.

${ }^{20}$ Mais informações sobre o trabalho de Hannah Wilke em: http://www.hannahwilke.com/. 
Um terceiro tipo de arte, na opinião de Barry e Flitterman, incorre também no erro do isolamento, encarando a ordem cultural dominante como uma construção monolítica, na qual a actividade cultural das mulheres é submersa. Esta posição é (irónica e habitualmente) assumida por dois grupos que as autoras denominam como "separatistas" e "não-feministas". No primeiro, encontram-se os artistas que não se identificam com um certo elitismo e os rígidos cânones da sua classe profissional e que pretendem, por essa razão, estabelecer a sua própria sociedade, na qual as mulheres possam combater o patriarcado (as autoras citam exemplos de grupos de teatro e outros projectos culturais exclusivamente organizados por mulheres lésbicas). No segundo grupo, encontram-se as mulheres artistas para quem o feminismo não faz qualquer sentido. Considerando-se essencialmente seres humanos que, por mero acaso, terão nascido mulheres, defendem que, no mundo artístico, não faz sentido ponderar-se o género dos seus autores, pelo que recusam igualmente uma contextualização social dos seus trabalhos. Neste contexto, as autoras citam as declarações da pintora expressionista, Elaine Kooning, ao afirmar: "Nós somos artistas e, por acaso, somos também mulheres ou homens, entre outras coisas - altos, baixos, loiros, morenos, mesomorfos, ectomorfos, negros, espanhóis, alemães, irlandeses, de temperamento difícil, fáceis de levar - que não são minimamente relevantes para o nosso trabalho enquanto artistas” (Barry et Flitterman, 1980: 43) ${ }^{21}$.

Por último, Barry e Flitterman apresentam a prática artística que elegem como o melhor meio para colocar as mulheres num lugar de destaque dentro do sistema patriarcal. A arte é aqui encarada como uma prática textual que explora as contradições sociais existentes uma vez que, nestes trabalhos, a imagem da mulher não é aceite como um dado adquirido, sendo antes construída durante o próprio processo criativo. Desta forma, consideram as autoras, é clarificada a ideia de que os significados são socialmente construídos (como defendia Saussure), demonstrando-se ainda a

${ }^{21}$ Tradução da autora. Versão original: "We're artists who happen to be women or men among other things we happen to be - tall, short, blonde, dark, mesomorph, ectomorph, black, Spanhish, German, Irish, hot-tempered, easy-going - that are in no way relevant to our being artists." 
importância e a função do discurso na formação da realidade social. $\mathrm{Na}$ opinião de ambas, fica ainda esclarecida a diferença entre "mulheres que criam arte numa sociedade dominada por homens" e "arte feminista que trabalha contra o patriarcado" (Barry et Flitterman, 1980: 44)22. Para além disso, uma abordagem teórica implica um corte com as noções dominantes de arte enquanto forma de expressão pessoal, associando-a antes às esferas social e política, o que atribui ao artista uma nova responsabilidade pelas imagens geradas. Se o activismo numa arte feita por mulheres se esbate em efeitos limitados - por não analisar a representação da mulher na cultura ou a produção das mulheres como uma categoria social - uma arte feminina terá necessariamente que evoluir a partir de uma reflexão teórica nas representações. Neste sentido, as autoras consideram fundamental que se questione como é produzida a representação das mulheres, de que forma aquela é entendida, e em que condições sociais ocorre. O vídeo Semiotics of the kitchen (Martha Rosler: 1975)²3 é dado como exemplo da utilização frustrada e raivosa de um léxico relacionado com a cozinha, enquanto dispositivo de manutenção das estruturas de poder instituído e divisão dos papéis atribuídos a cada género. Nas palavras das autoras: "Apenas através de um entendimento crítico da ‘representação’ é que uma re-presentação das 'mulheres' pode ocorrer" (Barry et Flitterman, 1980: 48)24. Um dos efeitos deste quarto tipo de arte é, nas suas opiniões, a evolução do estatuto do espectador de consumidor passivo para produtor activo de significados, que Annette Kuhn e Teresa de Lauretis viriam corroborar.

\section{Considerações finais}

Noutro contexto, o papel político da arte produzida por mulheres seria também sublinhado por Claire Johnston, na abertura da $31^{\mathrm{a}}$ edição do Festival de Cinema de Edimburgo (1979). Nesse ano, o conceituado festival

${ }^{22}$ Tradução da autora. Versão original: “(...) the difference between women making art in a male-dominated society and feminist art working against patriarchy."

23 Video disponível em: http://www.youtube.com/watch?v=3zSA9Rm2PZA

24 Tradução da autora. Versão original: "For it is only through a critical understanding of 'representation' that a re-presentation of 'women' can occur." 
de cinema apresentava, pela primeira vez, uma secção de filmes realizados por mulheres, o que ajudaria, no entender da autora, a compreender a forma como certas práticas culturais determinam a produção teórica. No discurso que mais tarde seria publicado na revista Screen (Johnston, 1982), sublinhava ainda que, no sentido inverso, a produção teórica também deveria alertar para o risco de encarar um texto fílmico como tendo uma efectividade específica, sem que se analise o contexto em que este foi visto. A autora propõe assim a criação de um pensamento e substrato teórico que analise a relação entre três factores distintos: texto, sujeito e conjuntura histórica. Não descartando a importância do trabalho de disciplinas como a semiótica e a psicanálise para o desenvolvimento das teorias feministas do cinema, e admitindo o seu papel fundamental em termos genealógicos, Claire Johnston sugere que se encare a produção fílmica como uma prática onde o reconhecimento e a identificação são fundamentais: "Eu defendo que qualquer projecto político como o feminismo, apesar de dever conter e preservar uma heterogeneidade de práticas sociais, deverá simultaneamente envolver uma forma de união imaginária para que se torne efectivo.” (Johnston, 1982: 29) 25.

Com os argumentos apresentados, a autora reitera a construção de uma certa unidade em torno das teorias feministas do cinema, com o objectivo de contrariar a subjectividade e a tendência de classificação da arte feminina como uma arte marginal, do outro, por oposição à patriarcal. Na sua opinião, "um dos projectos do movimento (feminista) é o de gerar conhecimento acerca da natureza e causas da opressão feminina, para que se possam delinear estratégias de transformação social" (Johnston, 1982: 28)²6, sendo, por essa razão, necessário reconhecer e identificar o poder e a função das estratégias políticas nas práticas fílmicas feministas. Neste sentido, afirma, a prática fílmica feminista deverá deixar de ser analisada em termos da

25 Tradução da autora. Versão original: "I would argue that any political project such as feminism, while it must contain and preserve a heterogeneity of social practices, must at the same time, involve a form of imaginary unity for it to be at all effective."

${ }^{26}$ Tradução da autora. Versão original: “... one of the projects of the movement is to construct knowledge of the nature and causes of women's oppression in order to devise strategies for social transformation." 
efectividade de um sistema de representação, mas antes como uma produção realizada por sujeitos com práticas sociais específicas e há muito delineadas: "Por outras palavras, a prática fílmica feminista é determinada por conjunturas de práticas discursivas, económicas e políticas, que produzem sujeitos na história” (Johnston, 1982: 30)27.

Alertando para a imprevisibilidade da análise e interpretação fílmicas, Johnston defende que uma análise conjuntural englobe aspectos como a representação ideológica e o contexto político, económico e social, pelo que também deverá passar a encarar-se o cinema como uma prática social: “A importância que a semiótica e a psicanálise atribuíram ao filme enquanto linguagem, como uma prática específica de significação, é crucial uma vez que encara o filme como um processo, um discurso que simultaneamente coloca no seu lugar um 'eu' e um 'tu'. Mas, como eu argumentei, há também um elemento exterior ao discurso, que tem uma efectividade e que deve ser levado em consideração quando o objectivo é desenvolver uma estratégia produtiva para uma luta ideológica relativa às teorias e práticas feministas do cinema" (Johnston, 1982: 34)28. Contestando a noção de leitor como uma construção teórica, Claire Johnston defende que os verdadeiros leitores são sujeitos históricos, em vez de sujeitos de um texto único.

Seria desta forma, proferindo um discurso linear e pragmático, que Claire Johnston inauguraria uma fase de crítica feminista às próprias teorias feministas do cinema. Na sua opinião, e na de muitas autoras que aprofundaram a temática subsequentemente, uma arte produzida por mulheres que se posicionam a si próprias como "o outro", o "negativo" ou "essencialmente femininas" (desenvolvendo um feminismo unificador e excludente) poderá ser um contributo essencial para a continuidade da

${ }^{27}$ Tradução da autora. Versão original: "In other words, feminist film practice is determined by the conjuncture of discursive, economic and political practices which produce subjects in history."

28 Tradução da autora. Versão original: "The stress that semiotics and psychoanalysis has placed on film as a language, as a specific signifying practice, is crucial because it poses film as a process, a discourse which simultaneously puts into place an 'I' and a 'you'. But as I have argued, there is also an outside of discourse which has an effectivity and which must be taken into consideration if a productive strategy for ideological struggle in relation to feminist film theory and practice is to be developed." 
predominância artística masculina. Justificando assim a escolha do título do seu artigo mais polémico - $O$ cinema realizado por mulheres como um "contra-cinema" (Johnston, 1973)-, Claire Johnston manifesta uma posição pouco idealista acerca dos processos criativos. Na sua opinião, um filme, como qualquer obra de arte, é produto de um sistema gerido por relações económicas (formulação que estende a filmes comerciais, políticos e experimentais).

Rejeitando uma concepção de arte universal e potencialmente andrógina, a autora defende o seu carácter discursivo, inserido numa conjuntura particular. Neste sentido, o cinema terá sido perpetuado por uma ideologia masculina, sexista, burguesa e capitalista. Considerando que o cinema não é neutro e que o olhar da câmara não capta a realidade tal como ela é (mas antes aquilo que a ideologia dominante pretende), Claire Johnston defende que um cinema realizado por mulheres não comporta visões românticas e idealistas: “(...)a 'verdade' da nossa opressão não pode ser 'captada' em celulóide com a 'inocência' da câmara: tem de ser construída/manufacturada. Novos significados têm de ser criados rompendo com a fábrica da ideologia burguesa masculina dentro do texto fílmico" (Johnston, 1973: 29)29. Para Claire Johnston, qualquer estratégia revolucionária deverá, deste modo, ultrapassar a análise artística, interrogando o cinema burguês e masculino até aí dominante. $\mathrm{O}$ risco de desenvolvimento de um cinema não interventivo foi consagrado, na sua opinião, por realizadoras como Agnès Varda, a quem não poupa críticas cerradas: "Não há dúvida que o trabalho de Varda é reaccionário: na sua rejeição da cultura e na colocação da mulher fora da história, os seus filmes marcam um passo retrógrado no cinema realizado por mulheres" (Johnston, 1973: 30)30.

29 Tradução da autora. Versão original: “... the 'truth' of our oppression cannot be 'captured' on celluloid with the 'innocence' of the camera: it has to be constructed/manufactured. New meanings have to be created by disrupting the fabric of the male bourgeois cinema within the text of the film."

30 Tradução da autora. Versão original: “There is no doubt that Varda's work is reactionary: in her rejection of culture and her placement of woman outside history her films mark a retrograde step in women's cinema."

93 
Discordando deste ponto de vista, consideramos que tentar descobrir uma estética feminina, um tema comum ou um olhar feminino no cinema, equivale a catalogar e a seccionar todo um vasto conjunto de obras de arte que têm sido produzidas, essencialmente, ao longo das últimas décadas. Fará sentido falar de filmes de mulheres, livros de mulheres, um traço de mulheres? Não existirão tantos filmes de mulheres quantos tipos de personalidades de mulheres, o mesmo se aplicando a todas as outras artes? Não estará Judith Butler correcta ao listar uma série de gender trouble como potenciais geradores de novos estereótipos e cânones excludentes de visões, experiências e sexualidades alternativas? Não corresponderá o feminino às eternas exigências e desigualdades que foram dirigidas a um segundo sexo, ao longo de toda a História da Humanidade?

Por outro lado, Iris Young considera que insistir na generalização forçada da conceptualização "ser mulher" tem como principal consequência o reforço dos privilégios "daqueles que mais beneficiam mantendo as mulheres divididas" (Young, 2004: 118, 119), para além de retirar consistência às políticas feministas. No seu entender, esta consciencialização é fundamental para que as próprias mulheres deixem de encarar os seus problemas e sofrimentos como naturais ou meramente pessoais, procedendo-se a uma conceptualização da opressão como um processo sistemático, estrutural e institucional. Neste sentido, e consciente dos obstáculos já enumerados, a autora propõe que, em vez de grupo ou colectivo, se utilize o conceito "serialidade”, desenvolvido por Sartre em Crítica da razão dialéctica, para referência futura a um conjunto potencialmente infinito de mulheres. Na sua opinião, o género encarado como uma série social - um tipo específico de colectividade que Sartre distingue dos grupos - tem como principais vantagens não exigir uma partilha de atributos, interesses, objectivos, contexto ou identidade: "Numa serialidade, a pessoa sente não apenas os outros, mas também a si própria como um Outro, isto é, como alguém anónimo: todos são o mesmo que o outro na medida em que cada um é Outro além de si próprio" (Young, 2004: 125). 
Conjugando todas as reflexões teóricas mencionadas, diríamos que buscar uma estética feminina é um processo que ultrapassa a canonização de traços identitários comuns, excludentes, estereotipados e socialmente rígidos. Buscar esta mesma estética será antes reconhecer a possibilidade de uma troca de experiências (noção tão cara aos estudos sobre mulheres por englobar, em si, subjectividade, sexualidade, corpo, educação e política), e a partilha de uma estrutura prático-inerte, essa sim, comum a todas as mulheres (que poderão, ou não, definir-se como tal).

\section{Referências bibliográficas}

AKERMAN, Chantal, (1977). Chantal Akerman on Jeanne Dielman. In : Camera Obscura, $\mathrm{n}^{\circ} 2$ (Fall). Duke University Press, pp. 114-121.

BARRY, Judith et FLITTERMAN, Sandy. (1980). Textual strategies: the politics of art-making. In: Screen, $\mathrm{n}^{\mathrm{O}} 21$ (2, Summer). Oxford Journals, pp 35-48.

BEAUVOIR, Simone, (1976). O Segundo Sexo - Factos e Mitos $\left(1^{o} e 2^{o}\right.$ volumes). Venda Nova: Bertrand Editora.

BOVENSCHEN, Silvia, (1977), Is there a feminine aesthetic? In: New German Critique, $\mathrm{n}^{\mathrm{0}} 10$ (Winter). Stanford University: Duke University Press, pp 111-137.

BUTLER, Judith (1999). Gender trouble - feminism and the subversion of identity. New York and London: Routledge.

FRENCH, Lisa, (2007). Centring the female: the articulation of female experience in the films of Jane Campion. Melbourne: RMIT University.

HOOKS, bell, (1999). Ain't I a woman: black women and feminism. Cambridge: South End Press.

JOHNSTON, Claire (1973). Notes on Women's Cinema. London: Society for Education in Film and Television.

JOHNSTON, Claire, (1982). The subject of feminist film theory/practice. In: Screen, $\mathrm{n}^{\mathrm{O}} 21$ (2, Summer). Oxford Journals, pp 27-34.

LAURETIS, Teresa, (1985). Aesthetic and feminist theory: rethinking women's cinema. In: New German Critique, $\mathrm{n}^{\mathrm{O}} 34$ (Winter). Stanford University: Duke University Press, pp 154-175.

MULVEY, Laura, (1989). Film, feminism and the avant-garde. In: Visual and other pleasures. London: Palgrave MacMillan, pp 115-131. 
YOUNG, Iris, (2004). O gênero como serialidade: pensar as mulheres como um colectivo social. In Revista Ex Aequo - Associação Portuguesa de Estudos das Mulheres, $n^{0}$ 8. Porto: Celta Editora. 